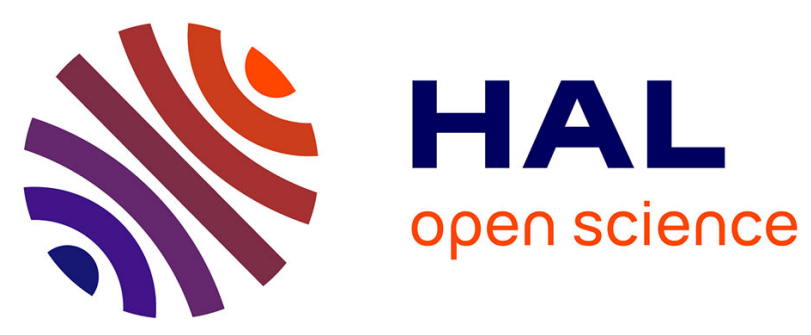

\title{
Qualitative and Semiquantitative Assessment of Exposure to Engineered Nanomaterials within the French EpiNano Program: Inter- and Intramethod Reliability Study
}

Irina Guseva Canu, Delphine Jezewski-Serra, Laurène Delabre, Stéphane Ducamp, Sabine Audignon-Durand, Yuriko Iwatsubo, Cécile Ducros, Anca Radauceanu, Catherine Durand, Olivier Witschger, et al.

\section{- To cite this version:}

Irina Guseva Canu, Delphine Jezewski-Serra, Laurène Delabre, Stéphane Ducamp, Sabine AudignonDurand, et al.. Qualitative and Semiquantitative Assessment of Exposure to Engineered Nanomaterials within the French EpiNano Program: Inter- and Intramethod Reliability Study. Annals of Work Exposures and Health, 2017, 61 (1), pp.87-97. 10.1093/annweh/wxw008 . hal-01539544

\author{
HAL Id: hal-01539544 \\ https://hal.science/hal-01539544
}

Submitted on 15 Jun 2017

HAL is a multi-disciplinary open access archive for the deposit and dissemination of scientific research documents, whether they are published or not. The documents may come from teaching and research institutions in France or abroad, or from public or private research centers.
L'archive ouverte pluridisciplinaire HAL, est destinée au dépôt et à la diffusion de documents scientifiques de niveau recherche, publiés ou non, émanant des établissements d'enseignement et de recherche français ou étrangers, des laboratoires publics ou privés. 


\section{Open Archive TOULOUSE Archive Ouverte (OATAO)}

OATAO is an open access repository that collects the work of Toulouse researchers and makes it freely available over the web where possible.

This is an author-deposited version published in : http://oatao.univ-toulouse.fr/ Eprints ID : 17893

To link to this article : DOI:10.1093/annweh/wxw008 URL : http://dx.doi.org/10.1093/annweh/wxw008

To cite this version : Guseva Canu, Irina and Jezewski-Serra, Delphine and Delabre, Laurène and Ducamp, Stéphane and Iwatsubo, Yuriko and Audignon-Durand, Sabine and Ducros, Cécile and Radauceanu, Anca and Durand, Catherine and Witschger, Olivier and Flahaut, Emmanuel Qualitative and Semiquantitative Assessment of Exposure to Engineered Nanomaterials within the French EpiNano Program: Inter- and Intramethod Reliability Study. (2017) The Annals of Occupational Hygiene, vol. 61 ( $\left.\mathrm{n}^{\circ} 1\right)$. pp. 87-97. ISSN 1475-3162

Any correspondence concerning this service should be sent to the repository administrator: staff-oatao@,listes-diff.inp-toulouse.fr 


\title{
Qualitative and Semiquantitative Assessment of Exposure to Engineered Nanomaterials within the French EpiNano Program: Inter- and Intramethod Reliability Study
}

\author{
Irina Guseva Canu1*, Delphine Jezewski-Serra1, Laurène Delabre', \\ Stéphane Ducamp ${ }^{1,2}$, Yuriko Iwatsubo1, Sabine Audignon-Durand², \\ Cécile Ducros ${ }^{3}$, Anca Radauceanu ${ }^{4}$, Catherine Durand ${ }^{3}$, Olivier Witschger ${ }^{5}$ \\ and Emmanuel Flahaut ${ }^{6}$
}

'Direction Santé Travail, Santé publique France, F-94415 Saint-Maurice, France; '2Laboratoire Santé Travail Environnement, Université de Bordeaux-Segalen, F-33076 Bordeaux, France; ${ }^{2}$ Plate-forme NanoSécurité, CEA-Grenoble, F-38054 Grenoble, France; ${ }^{4}$ Département Épidémiologie en Entreprise, Institut National de Recherche et de Sécurité pour la prévention des accidents de travail et des maladies professionnelles (INRS), F-54519 Vandoeuvre, France; 5'Laboratoire de Métrologie des Aérosols, INRS, F-54519 Vandoeuvre, France; ${ }^{6}$ Centre Interuniversitaire de Recherche et d'Ingénierie des Matériaux, Université Paul Sabatier, F-31062 Toulouse, France

*Author to whom correspondence should be addressed. Tel: +33-1-41795734; e-mail: Irina.GUSEVACANU@santepubliquefrance.fr; irinacanu@hotmail.com

\begin{abstract}
The relatively recent development of industries working with nanomaterials has created challenges for exposure assessment. In this article, we propose a relatively simple approach to assessing nanomaterial exposures for the purposes of epidemiological studies of workers in these industries. This method consists of an onsite industrial hygiene visit of facilities carried out individually and a description of workstations where nano-objects and their agglomerates and aggregates (NOAA) are present using a standardized tool, the Onsite technical logbook. To assess its reliability, we implemented this approach for assessing exposure to NOAA in workplaces at seven workstations which synthesize and functionalize carbon nanotubes. The prediction of exposure to NOAA using this method exhibited substantial agreement with that of the reference method, the latter being based on an onsite group visit, an expert's report and exposure measurements (Cohen kappa $=0.70$, sensitivity $=0.88$, specificity $=0.92$ ). Intramethod comparison of results for exposure prediction showed moderate agreement between the three evaluators (two program team evaluators and one external
\end{abstract}


evaluator) (weighted Fleiss kappa $=0.60, P=0.003$ ). Interevaluator reliability of the semiquantitative exposure characterization results was excellent between the two evaluators from the program team (Spearman rho $=0.93, P=0.03$ ) and fair when these two evaluators' results were compared with the external evaluator's results. The project was undertaken within the framework of the French epidemiological surveillance program EpiNano. This study allowed a first reliability assessment of the EpiNano method. However, to further validate this method a comparison with robust quantitative exposure measurement data is necessary.

Keywords: epidemiology; exposure registry; inhalation; nano-objects and their agglomerates and aggregates (NOAA); occupational exposure

\section{Introduction}

Obtaining relevant and accurate information about occupational exposures is often challenging, particularly for epidemiological studies in which researchers may have limited access to a worksite and relevant records. Exposure assessment for epidemiological studies of occupational exposure to airborne nano-objects and their agglomerates and aggregates (NOAA) has been especially challenging because relevant, accurate, systematically collected data are almost inexistent.

There are at least five explanations for this, which may also explain the rarity of related epidemiological studies on workers (Liao et al., 2014a,b; Wu et al., 2014). First, NOAA is a relatively new field of research and its penetration in industry is still limited, but growing rapidly. Second, industry protects their intellectual property, which makes it difficult to systematically collect exposure data. Third, toxicologists still do not have consensus on the exposure metric to use and on the specific NOAA physicochemical characteristics most relevant to potential adverse biological effects (and the metric could differ by nanomaterial/application type/situation). In fact, in the absence of precise recommendations on what to measure, the current recommendation is simply 'to measure every metric if possible'. Although conversion from one metric to another could be an option for the meantime, for some type of NOAA, such as CNTs it could be more complex, given that agglomeration state modifies their density and thus solubility after deposition in the respiratory tract (Guseva Canu et al., 2015a). Fourth, currently there is no coordinated strategy for exposure assessment that can be easily implemented across the variety of workplaces in which NOAA exposure occurs. That said, the OECD has recently provided a Harmonized Tiered Approach to NOAA exposure assessment (OECD, 2015). Fifth, NOAA exposure assessment is hampered by a shortage of equipment and methodologies to analyze their physicochemical characteristics and their large heterogeneity (Brouwer et al., 2013; Dahm et al., 2013; Honnert and Grzebyk, 2014; Bekker et al., 2015).
While waiting for harmonized guidelines on how to assess and manage exposure to NOAA (as well as nanocomposites and nano-products), in 2014 the French government launched the national program 'EpiNano', to survey the possible mid- and long-term health effects of occupational exposure to carbon nanotubes $(\mathrm{CNT})$ and titanium dioxide nanoparticles $\left(\mathrm{TiO}_{2}\right)(\mathrm{Canu}$ et al., 2013). EpiNano is limited to workers potentially exposed to these NOAA, essentially via inhalation. In order to identify those workers in companies dealing with these materials and register them in the EpiNano exposure registry, with the view to implementing a prospective epidemiological follow-up of their health, a standardized exposure assessment method was developed (Guseva Canu et al., 2015 b,c). This observational method was designed to enable epidemiologists and occupational physicians to asses, in a structured way, the qualitative potential for release of NOAA into the workplace air, resulting from processes and handling of $\mathrm{CNT}$ and $\mathrm{TiO}_{2}$.

The aim of the present work was to investigate the validity of the method developed for the identification of workplaces, workstations, activities/tasks, and of workers potentially exposed to NOAA, and to assess the interevaluator agreement for the determination of potential exposure to NOAA.

\section{Materials and Methods}

\section{Study setting}

For this study, the following selection criteria were implemented to choose a private employer or public research laboratory as the study setting for this evaluation: (i) The facility had to agree to collaborate with the EpiNano project team, (ii) There had to be more than five workstations in the facility where CNT and/ or $\mathrm{TiO}_{2}$ was used, (iii) The facility had to have already participated in a previous NOAA exposure assessment performed by external experts and/or in exposure measurement programs, (iv) It had to agree to provide all available exposure data for the intermethod reliabil- 
ity study, and (v) It had to agree to an onsite facility visit by an external evaluator.

The facility selected for this study is part of an interuniversity center for material research and engineering, created in 1999. This facility specializes in the synthesis and filling of CNT and related applications to composites and nanoelectronics. In 2010, this facility participated in an exposure monitoring campaign as part of the NanoINNOV project (Zimmermann et al., 2012). A senior researcher in charge of research programs in this facility actively participated in that and other projects. Providing us with the floor plan of the facility, this expert indicated workstations where CNT (in this case NOAA) were potentially present or occasionally emitted. Accordingly, seven workstations were preselected for detailed observation during the onsite exposure assessment visit. Note that this expert did not perform the task of evaluator at any point, as depicted in Supplementary Information, Document S1 (Figure S1) at Annals of Work Exposures and Health online.

\section{Exposure assessment method}

The exposure assessment method consists of an onsite visit to the facility (in this case the university research facility) conducted separately by individual internal and external evaluators. It uses the Onsite technical logbook, a tool developed by Quintet ExpoNano, a multidisciplinary working group which includes national experts in NOAA inhalation exposure assessment, industrial hygiene, occupational medicine, and epidemiology, provided in Supplementary Information, Document S2 at Annals of Work Exposures and Health online. The EpiNano method, the logbook development, and its use are all described in detail elsewhere (InVS, 2013; Guseva Canu et al., 2015b, c).

The logbook enables EpiNano team members to standardize onsite observation and data collection in order to identify the workstations possibly causing exposure to NOAA, and to assess this potential exposure. For this, three kinds of exposure variables are used: (i) binary exposure status [dichotomous (exposed/not exposed) variable], (ii) quantitative continuous exposure score (continuous quantitative variable), and (iii) ordinal semiquantitative exposure potential (four-class categorical variable). The quantitative exposure score can be calculated in different ways, dependent on the model chosen (Guseva Canu et al., 2016). For this study, the most comprehensive and most robust (Riedmann et al., 2015) source-receptor exposure model (Schneider et al., 2011) was retained, using the exposure determinants and formula of the quantitative unitless exposure score from the Stoffenmanager program (Marquart et al.,
2008) and values of weighting factors from the Stoffenmanager Nano, version 1.0 (Duuren-Stuurman et al., 2012), a NOAA-specific module of the program. Binary exposure was assessed entirely by each of the individual evaluators. Instead, variables 2 and 3 were evaluated using custom-made data management software, based on data collected in the logbook and computerized by evaluators after the onsite visit.

\section{Intermethod comparison}

Intermethod reliability is a measure of the ability of two different methods which evaluate the same underlying exposure to yield similar results on the same subjects (White et al., 2008). In this study, we compared an observational exposure assessment method to be used in the EpiNano survey (EpiNano method) with a more accurate but more complex method (Reference method) (Supplementary Figure S1 is available at Annals of Work Exposures and Health online). Consequently, the present study could be interpreted as a relative validity study.

Although expert assessment of occupational exposure is often criticized, it continues to be considered the method of reference for observational studies (Bourgkard et al., 2013; Burstyn et al., 2014; Hunt et al., 2015; Wild et al., 2016). The better the expert and the greater the quantity and quality of data, the better the assessment will be (White et al., 2008). Given that no goldstandard method exists for quantifying exposure to CNTs in workplaces (Guseva Canu et al., 2015a), and that there was no possibility to perform an ad-hoc exposure monitoring for the evaluation study of our EpiNano method, we were constrained to use a combination of available resources, debriefing of results, and consensus meetings. More specifically, this involved, an onsite visit, interviews with operators and supervisors, analyzing results of exposure measurements from a previous campaign (in this case from the NanoINNOV project), a debriefing meeting and an expert's report to validate results through consensus (Supplementary Figure S1 is available at Annals of Work Exposures and Health online).

\section{Reference method}

In January 2014, a comprehensive review of the preselected seven workstations dealing with CNTs at the facility was performed. During the onsite group visit, three EpiNano project team members (one epidemiologist and two occupational hygienists) were accompanied by the expert (see Study setting above), an occupational physician and an assistant engineer in charge of occupational hygiene and safety. Each workstation was examined and all potential exposure scenarios were con- 
sidered based on one-to-one interviews with workstation users (researchers, students, technicians, and engineers). Details about the workstations' configurations and operational conditions were thoroughly recorded. Each evaluator filled in the Onsite technical logbook. The day after the onsite visit, a debriefing meeting was held to review and complete the collected information and notes taken. Conclusions from the previous 2010 exposure measurement campaign (summarized in supplementary Document S1 at Annals of Work Exposures and Health online) and the expert's knowledge were also considered (Supplementary Figure S1 is available at Annals of Work Exposures and Health online). Onsite technical logbooks completed by the three evaluators were compared and discrepancies discussed in order to reach a consensus and produce a definitive version of the Onsite technical logbook. This final version was then computerized by one of evaluators and sent to the expert together with proceedings of the session for final verification and validation.

Selection of evaluators for validating the EpiNano method The EpiNano method was implemented by three evaluators: two experienced evaluators from the EpiNano program team, Evaluators \#1 and \#2 (one epidemiologist and one industrial hygienist), and one nonexperienced external evaluator, Evaluator \#3. The external evaluator is an industrial hygienist from a research laboratory with 10 years' experience in occupational epidemiological studies but unfamiliar with NOAA-handling facilities. The external evaluator did not take part of the EpiNano training program before this study nor did he participate in any prestudy onsite exposure assessment visits. These conditions were imposed in order to represent the worst case scenario, i.e. implementation of the EpiNano method by a professional unfamiliar with this method and with its use during an onsite visit.

\section{Procedure of exposure assessment and data management} for the EpiNano method

The EpiNano method was implemented at the facility in July 2014. Each evaluator was asked to individually conduct the onsite visit of the facility, and to fill in the Onsite technical logbook, based on their own observation of the workstations and interviews with the staff present at the facility (Supplementary Figure S1 is available at Annals of Work Exposures and Health online). In order to assure the independency of their individual exposure assessment, the evaluators did not have access to the assessments obtained by evaluators using the reference method 6 months previously in January 2014, or to their peers' individual exposure assessments. After completing their respective exposure assessment, each evaluator was asked to input the information collected by them in the Onsite technical logbook via user-friendly online software designed for the program. This custommade software is visually similar to the Onsite technical logbook, which facilitates data entry. Moreover, using integrated quality control in terms of accuracy of data coding and capture, this software also facilitates further processing of data. Once computerized, the data display makes it easier to classify workstations with respect to their potential exposure to NOAA.

The external evaluator was provided with the Onsite technical logbook one month before the session and was trained in the use of data-entering software by an experienced evaluator from the project team, participating in this study as one of internal evaluators.

The computerized data were processed and analyzed, the evaluators' identities remaining undisclosed using Stata V.12 (StataCorp, College Station, TX, USA).

\section{Statistical analysis}

Since the objective of this study was to assess the validity of the EpiNano method, the main analyses compared the exposure assessed using this method (Onsite technical logbook) with the Reference method [Onsite technical logbook + exposure measurement results and expert's knowledge + consensus between three evaluators and expert (Supplementary Figure S1 is available at Annals of Work Exposures and Health online)], which was taken as a gold standard. Depending on the type of exposure variable, different statistics were measured in order to quantify the agreement between the two methods. For the binary exposure status variable, sensitivity, and specificity were used as measures of the method validity. The method's sensitivity is the ability to correctly identify those workstations with the exposure characteristic of interest. Specificity is the ability to correctly identify unexposed workstations which do not have the exposure characteristic of interest (Brenner and Gefeller, 1997). Furthermore, the percentage of exact agreement and chance-corrected agreement based on Cohen's kappa $(\kappa)$ statistic were calculated (Rajaraman and Samet, 2005). Kappa values were interpreted according to the criteria defined by Landis and Koch (1977). Values greater than 0.80 represent very good agreement beyond chance, values between 0.60 and 0.80 represent good agreement, values between 0.40 and 0.60 represent moderate agreement, values between 0.20 and 0.40 represent fair agreement, and values below 0.20 represent poor agreement (Landis and Koch, 1977). For the quantitative exposure score variable, Spearman's correlation coefficient, rho $(\rho)$ (Spearman, 1904) 
was used. This nonparametric method serves to identify monotone correlations between two variables with skewed distribution. It compares the workstations' classification resulting from the calculated exposure score using data obtained from the EpiNano method. The resulting classification is based on the Reference method data. Correlation significance was tested with a $5 \%$ error risk. The $\rho$-values were interpreted as follows: values between 0.1 and 0.3 imply weak correlation; values between 0.3 and 0.5 imply moderate correlation, and values above 0.5 imply strong correlation (Cohen, 1988). Finally, for ordinal semiquantitative variable, the measurement of intermethod agreement was calculated using the weighted kappa $\left(\kappa_{\mathrm{w}}\right)$ statistic (Cohen, 1968). Since the intermethod comparison is limited to the statistical comparison of only two measures at one time, whereas the EpiNano method was implemented by three evaluators individually, all statistics were calculated based on pairwise comparisons of their respective results with the results from the Reference method.

\section{Intramethod comparison}

Intramethod reliability is a measure of the reproducibility of an instrument, either applied in the same manner to the same subjects at two points of time (test-retest reliability) or applied by two or more raters (termed 'evaluators' here) to the same subjects (inter-rater reliability study) (Nieuwenhuijsen, 2003). In this study, inter-rater reliability was assessed by comparing the results of three evaluators who implemented the EpiNano method in July 2014 (Supplementary Figure S1 is available at Annals of Work Exposures and Health online). In contrast with intermethod comparison, the intramethod reliability study focuses not on the reliability of the exposure assessment using the EpiNano or Reference method, but on the reproducibility of exposure measures irrespective of the evaluator performing the task.

\section{Statistical analysis}

Under the assumption that in the full epidemiological EpiNano study-destined to continue for the next 20 years-each workstation in the facilities investigated will be randomly assigned an exposure score (e.g. by one individual evaluator), another version of kappa, $\kappa_{\mathrm{F}}$ (Fleiss, 1999) was used here to estimate the reliability of the binary exposure assessment between the three evaluators. For inter-rater reliability of quantitative exposure score, the interclass correlation coefficient (Donner and Wells, 1986) was estimated from the one-way random effect model ANOVA. Bartlett's test was used for checking the assumptions of an analysis of variance (ANOVA;
Brown and Forsythe, 1974). Furthermore, the inter-rater reliability of the exposure score components in the form of categorical variables was assessed using $\kappa_{\mathrm{F}}$ statistic. Kappa values were interpreted according to Landis and Koch (1977). Finally, to compare the distributions of the ordinal semiquantitative exposure variable, Spearman correlation coefficients were calculated. The values of correlations coefficients were interpreted according to Cohen (1988).

\section{Results and Discussion}

Inter- and intramethod reliability assessment was based on the results of the exposure assessment performed at seven workstations evaluated during the onsite technical visit of the experimental facility. The main results from the two methods of exposure assessment are summarized in Table 1. Among the workstations observed, the number of workstations classified as potentially concerned by NOAA exposure ranged from two to four, depending on the evaluator. Nonetheless, no workstation was classified in the high exposure category, based on the quantitative exposure score. Examples of calculation of the quantitative exposure score are provided in Supplementary Document S1 (Supplementary Tables S1-S3 are available at Annals of Work Exposures and Health online).

\section{Intermethod validity \\ Validity of the binary exposure estimate}

Table 2 summarizes the results of the EpiNano method's reliability when classifying workstation NOAA exposure. Based on the estimated Cohen's kappa values of 70 or more percent, we concluded that there was substantial agreement, independent of chance, between the Reference method and the EpiNano method irrespective of the evaluator implementing the latter. Although observed agreement was $86 \%$ for all evaluators, the sensitivity and specificity of their exposure assessment using the EpiNano method were different. When this method was implemented by Evaluators \#1 or \#2, it was more specific than sensitive. This means that the EpiNano method correctly identified workstations with no potential exposure to NOAA (true negative) but misclassified every third workstation as unexposed when in fact it should have been classified 'potentially exposed' (false negative). In contrast, Evaluator \#3's results showed higher sensitivity than specificity (Table 2). When the EpiNano method was implemented by Evaluator \#3, it correctly classified those workstations potentially exposed to NOAA (true positive), but misclassified $25 \%$ of the workstations as potentially exposed when the Reference 
Table 1. Descriptive results of the exposure assessment using the EpiNano and Reference methods.

\begin{tabular}{|c|c|c|c|c|}
\hline & \multirow[t]{2}{*}{ Reference method } & \multicolumn{3}{|c|}{ EpiNano method } \\
\hline & & Evaluator \#1 & Evaluator \#2 & Evaluator \#3 \\
\hline Period of implementation & January 2014 & July 2014 & July 2014 & July 2014 \\
\hline $\begin{array}{l}\text { Workstations observed during onsite visit } \\
\text { (N) }\end{array}$ & 7 & 7 & 7 & 7 \\
\hline 1. CVD synthesis and harvesting of CNT & $\checkmark$ & $\checkmark$ & $\checkmark$ & $\checkmark$ \\
\hline 2. Weighing of CNT powder & $\checkmark$ & $\checkmark$ & $\checkmark$ & $\checkmark$ \\
\hline 3. Extraction by sonication & $\checkmark$ & $\checkmark$ & $\checkmark$ & $\checkmark$ \\
\hline 4. Chemical purification of CNT & $\checkmark$ & $\checkmark$ & $\checkmark$ & $\checkmark$ \\
\hline 5. Lyophilisation of CNT powder & $\checkmark$ & $\checkmark$ & $\checkmark$ & $\checkmark$ \\
\hline 6. Functionalization of CNT & $\checkmark$ & $\checkmark$ & $\checkmark$ & $\checkmark$ \\
\hline 7. Doping and filling of CNT & $\checkmark$ & $\checkmark$ & $\checkmark$ & $\checkmark$ \\
\hline $\begin{array}{l}\text { Workstations classified as potentially } \\
\text { concerned with CNT exposure (n, \%) }\end{array}$ & $3(43 \%)$ & $2(29 \%)$ & $2(29 \%)$ & $4(57 \%)$ \\
\hline $\begin{array}{l}\text { No. of workstations classified as } \\
\text { potentially concerned with CNT } \\
\text { exposure }\end{array}$ & $1,2,6$ & 1,2 & 1,2 & $1,2,3,5$ \\
\hline $\begin{array}{l}\text { Quantitative exposure score, unitless } \\
(\text { mean } \pm \text { SD })\end{array}$ & $0.001030 \pm 0.0024$ & $0.000433 \pm 0.0011$ & $0.000439 \pm 0.0006$ & $0.009399 \pm 0.01840$ \\
\hline \multicolumn{5}{|l|}{ Semiquantitaive exposure potential $(\mathrm{n}, \%)$} \\
\hline 1. Negligible to low $(<0.002)$ & $6(86 \%)$ & $6(86 \%)$ & $6(86 \%)$ & $5(72 \%)$ \\
\hline 2. Low to moderate $(0.002-0.2)$ & $1(14 \%)$ & $1(14 \%)$ & $1(14 \%)$ & $1(14 \%)$ \\
\hline 3. Moderate to high $(0.2-20)$ & $0(0 \%)$ & $0(0 \%)$ & $0(0 \%)$ & $1(14 \%)$ \\
\hline 4. Very high $(>20)$ & $0(0 \%)$ & $0(0 \%)$ & $0(0 \%)$ & $0(0 \%)$ \\
\hline
\end{tabular}

CNT, carbon nanotube; SD, standard deviation; CVD, chemical vapor deposition.

Table 2. Results of intermethod validity of EpiNano method for binary exposure assessment. Pairwise comparison of the onsite identification of workstations concerned with potential exposure to carbon nanotubes with results from the Reference method.

\begin{tabular}{|c|c|c|c|c|c|c|}
\hline Comparison & $\begin{array}{c}\text { Observed } \\
\text { agreement } \\
(\%)\end{array}$ & $\begin{array}{c}\text { Expected } \\
\text { agreement } \\
(\%)\end{array}$ & Карра & $P$ & Sensitivity & Specificity \\
\hline Reference versus & 86 & 53 & $0.70^{\mathrm{a}}$ & 0.027 & 0.67 & 1.00 \\
\hline \multicolumn{7}{|l|}{ Evaluator \#1 } \\
\hline Reference versus & 86 & 53 & $0.70^{\mathrm{a}}$ & 0.027 & 0.67 & 1.00 \\
\hline \multicolumn{7}{|l|}{ Evaluator \#2 } \\
\hline Reference versus & 86 & 49 & $0.72^{a}$ & 0.023 & 1.00 & 0.75 \\
\hline \multicolumn{7}{|l|}{ Evaluator \#3 } \\
\hline Overall validity & 86 & 52 & $0.70^{\mathrm{b}}$ & 0.03 & 0.88 & 0.92 \\
\hline
\end{tabular}

${ }^{\mathrm{a}}$ Cohen kappa.

${ }^{\mathrm{b}}$ Fleiss kappa.

method classified them as unexposed (false positive). The results of the overall intermethod reliability were satisfactory, and show that EpiNano method accurately predicts binary exposure status. However, the higher specificity $(\mathrm{Sp}=0.92)$ than sensitivity $(\mathrm{Se}=0.88)$ of the method was unexpected, given that only potentially exposed workers were eligible for the prospective epidemiological surveillance program. This result is even more surprising because Evaluators \#1 and \#2 are members of the EpiNano team and implement the EpiNano method 
on a regular basis (twice a month) during onsite visits to companies participating in the EpiNano program.

Validity of the quantitative exposure score and semiquantitative exposure potential

The results of the comparison between the calculated quantitative exposure scores based on data from Reference method and data from EpiNano method, as assessed in pairwise correlation coefficients (for the three evaluators) are shown in Table 3.

The best reliability was found for the EpiNano method results of Evaluator \#1, when comparing with the Reference method (Spearman's $\rho=0.75$, indicating substantial positive correlation). For Evaluator \#2, the correlation was also positive (Spearman's $\rho=0.57$ ), but of moderate strength and not statistically significant. The poorest reliability was obtained for Evaluator \#3 with a very negative correlation. Since the quantitative exposure score was constructed as a combination of several exposure determinants (Supplementary Table S1 is available at Annals of Work Exposures and Health online)-each parameter of the score being independently assessed in both Reference and EpiNano methods-additional analysis was conducted to identify the worst correlated determinants, based on nonparametric Spearman's correlation method. From the determinants assessed, only three displayed weak correlations (Spearman's $\rho<0.30$ ): '2.3: weight fraction of NOAA in the product', ' 3 : local control of exposure due to near-field sources', and '4: type and effect of general ventilation' (Results not shown).

Although some discrepancies were observed when comparing the calculated quantitative exposure score, as assessed using EpiNano method, with those assessed using the Reference method, almost perfect correlation was found when comparing the semiquantitative exposure potential variable. This four-class variable was obtained by categorizing quantitative exposure score (Table 1 and Supplementary Table S1 is available at Annals of Work Exposures and Health online). All

Table 3. Results of intermethod comparison of EpiNano method for quantitative exposure assessment. Pairwise correlation between quantitative exposure scores obtained from EpiNano and from Reference methods.

\begin{tabular}{lcc}
\hline Comparison & Spearman's $\rho$ & $P$ \\
\hline Reference versus Evaluator \#1 & 0.75 & 0.05 \\
Reference versus Evaluator \#2 & 0.57 & 0.18 \\
Reference versus Evaluator \#3 & -0.50 & 0.25 \\
\hline
\end{tabular}

but one workstation were classified in the first category corresponding to 'negligible to low' exposure potential.

\section{Inter-rater reliability}

Inter-rater reliability of the binary exposure estimate

The results of pairwise comparison of the onsite identification of workstations concerned by CNT exposure with results from the Reference method are presented in Table 4. Very good agreement beyond chance was observed between the results of Evaluator \#1 and Evaluator \#2, based on $100 \%$ observed agreement. Agreement between Evaluator \#3 and the two other evaluators was moderate (Cohen's $\kappa=0.46$ ). This result is not surprising since Evaluators \#1 and \#2 are EpiNano program team members, while Evaluator \#3 is external. Moreover, he neither took part in the EpiNano training program before this study nor participated in any pre-study onsite exposure assessment visits. In fact, these two conditions were imposed in order to represent the worst case scenario, i.e. implementation of the EpiNano method by a professional not familiar with this method or its onsite implementation. The overall inter-rater reliability was good, based on the weighted Fleiss's kappa value $\left(\kappa_{\mathrm{F}}=0.60, P=0.03\right)$.

Inter-rater reliability of the quantitative exposure score and semiquantitative exposure potential

The results of one-way ANOVA for the inter-rater reliability study of quantitative exposure score are summarized in Table 5. The result of Bartlett's test for equal variance between three evaluators $\left(\chi^{2}(2)=4.78, P=0.09\right)$ did not allow the null hypothesis. The estimated interclass correlation coefficient was low (ICC $=0.032$ ) with the $95 \%$ confidence interval ranging from 0.00 to 0.37 .

The examination of the exposure score constituents based on weighted kappa statistic $\left(\kappa_{\mathrm{w}}\right)$ allowed us to identify five determinants with $\kappa_{\mathrm{w}}<0.30$ (2.3: weight fraction of NOAA in the product, 4: reduction of exposure by general ventilation, 3 : local control of exposure due to near-field sources, 7: background emission from deposited contaminants, and 7.1: inspections and maintenance of machines-results not shown here) which could likely explain the discrepancy observed between quantitative scores of three evaluators. However, in accordance with intermethod reliability study result, an excellent inter-rater agreement was observed for semiquantitative exposure assessment, in terms of the four-class exposure potential.

\section{Interpretation of the study findings}

In order to correctly interpret the results of these intermethod validity and inter-rater reliability studies, some methodological or logistic issues must be addressed. 
Table 4. Results of inter-rater reliability of the EpiNano method for binary exposure assessment. Pairwise comparison of the onsite identification of workstations concerned with potential exposure to carbon nanotubes between three evaluators.

\begin{tabular}{|c|c|c|c|c|}
\hline Comparison & $\begin{array}{c}\text { Observed } \\
\text { agreement } \\
(\%)\end{array}$ & $\begin{array}{l}\text { Expected } \\
\text { agreement } \\
(\%)\end{array}$ & $\begin{array}{l}\text { Cohen's } \\
\text { kappa }\end{array}$ & $P$ \\
\hline Evaluator \#1 versus Evaluator \#2 & 100 & 59 & 1.00 & 0.004 \\
\hline Evaluator \#1 versus Evaluator \#3 & 71 & 47 & 0.46 & 0.072 \\
\hline Evaluator \#2 versus Evaluator \#3 & 71 & 47 & 0.46 & 0.072 \\
\hline
\end{tabular}

Table 5. Results of one-way ANOVA for the inter-reader reliability study of quantitative exposure score from EpiNano method.

\begin{tabular}{lccr}
\hline Source of variance & Sum of squares & Degree of freedom & Mean square \\
\hline Between evaluators & 0.000001607 & 2 & 0.00000080 \\
Within evaluators (random error) & 0.000011757 & 18 & 0.00000065 \\
Total & 0.000013365 & 20 & 0.00000067 \\
\hline
\end{tabular}

The first issue is the absence of the 'gold standard' data to quantify occupational exposure to CNT in this study. Although several methods have recently been proposed, based either on elemental carbon mass concentration measurements or on counting of CNT-containing structures in the personal breathing zone air samples, none is recognized as a reference method for quantifying exposure (Guseva Canu et al., 2015a). Nevertheless, such methods could be used to identify workstations with relatively high elemental carbon mass concentration and to classify them by exposure level. The availability of pre-existing exposure measurement data was an important criterion for selecting the experimental facility. However, only one facility agreed to participate in this study and to provide the results of an exposure measurement campaign. This campaign, conducted at the facility in 2010, was in line with an experimental research protocol and devices (Zimmermann et al., 2012). Exposure measurements results were available for only three workstations and were inconsistent with respect to current situation and the current guidelines for CNT exposure assessment (Guseva Canu et al., 2015a) (Supplementary Document S1 is available at Annals of Work Exposures and Health online). Consequently, the Reference method used in this study represents a combination of expert knowledge and observational data gathered using the standardized tool at the experimental facility by experienced evaluators, validated by expert consensus. The experimental facility is representative of public and mixed public-private research and development laboratories, but is not representative of industrial primary production and secondary manufacturing companies. Also, it is a potentially important limitation for a quantitative reliability study; we believe that it has little influence, especially concerning the validity of the binary exposure prediction using the EpiNano method. In fact, the research laboratory context-which includes the frequent changing of research projects resulting in changes in nanomaterial production or transformation processes, in input and output products, in creation of novel workstations and adaptation of the existing workstations for novel usages, as well as the constant turn-over of temporary staff (contracts last 3 and 2 years on average for $\mathrm{PhD}$ and postdoctoral fellows, respectively) and the high proportion of temporary staff compared with permanent staff (research engineers and technicians)—could be considered as corresponding to the worst case conditions for NOAA exposure assessment. Compared with stable production processes with automatized procedures in large industrial companies, which mostly employ permanent staff who are trained and often equipped with protective devices against inhalation of NOAA, the implementation of the EpiNano method is more difficult in a research laboratory. It could be that some operators present during the onsite visits might be interviewed more than once by different evaluators. However, for most workstations it was unlikely: most workstations are not limited to one particular operator and the onsite visits have been scheduled preferentially when all operational staff were present, in order to avoid interviewing the same person. Moreover, since all the items are notified and codified in a standardized tool by the evaluator in real time during the interview, the only impact of repeating interview could be a more systematic and more rapid description of the workstation by the operator, which is unlike to result in any recall bias in exposure assessment. 
Although the choice of the experimental facility, with its seven workstations dedicated to CNT production and transformation, was relevant with respect to variability of operations and CNT characteristics, it precluded assessing the method reliability with respect to other types of NOAA. However, since the EpiNano method has also been successfully implemented in facilities producing and manufacturing $\mathrm{TiO}_{2}$, including one industrial production company, it is unlikely that the results of this study would be different for other NOAA. Another limitation related to the choice of experimental facility was the very low quantities of NOAA handled and generated (a few grams instead of kilograms and tonnes). This limitation prevented any deeper exploration of the interrater variability of the results because of a narrow distribution of workstations according to exposure potential category.

The small number of workstations observed in this study was another limitation, although we included all the workstations dealing with NOAA at the facility. For more powerful statistical analyses, a larger set of occupational settings would be suitable, especially for a validation study of the quantitative exposure score. The fact that only three evaluators participated in this study also deserves discussion. Given the uncertainty about health effects of exposure to nanomaterials, and in order to avoid disturbing routine activities in the workplace, only a limited number of visitors are permitted at the onsite visits. This restriction guided our choice of three evaluators, two regular assessors from the EpiNano project-team (one occupational hygienist and one epidemiologist) and one external evaluator with generic competencies in occupational hygiene. The use of appropriate statistical methods and nonparametric tests allowed us comprehensively exploiting all the data collected and thus circumventing the issue of small number of evaluators involved in this study.

Despite these limitations, the implementation of the EpiNano method by three individual evaluators demonstrated satisfactory reliability to detect workstations which are potentially concerned by exposure to NOAA as well as a very good inter-rater agreement among evaluators of the EpiNano team, for binary, semiquantitative, and quantitative exposure assessment. Moreover, the EpiNano is in line with the OECD Harmonized Tiered Approach to NOAA exposure assessment (OECD, 2015), as it could be implemented as Tier 1 , for gathering information on the occupational workplace under consideration, including workplace activities and the materials handled in order to determine whether additional assessment is required before conducting a basic exposure or release assessment (Tier 2).
Implication of the study results and methodological improvements

The results of this study were presented in two meetings with study participants with the following objectives: first, to present the study findings and analyze the discrepancies between Reference and EpiNano method results, and second, to examine possible sources of the inter-evaluator discrepancies and define a common search approach for logistic and methodological improvements.

The exposure score constituents with lowest concordance between evaluators were also examined in light of the recent findings from the comparison and evaluation of multiple users' usage of the Stoffenmanager program (Landberg et al., 2015). In that study, local exposure control, ventilation and maintenance of equipment, personal protection equipment, and type of task were identified as parameters with lowest concordance between evaluators (Landberg et al., 2015). The authors partially explained this high discrepancy by a high number of items available for these parameters, which had a wide range of weighting factors' values. They also recognized that efficiency of ventilation and local exposure control measures are difficult to assess, as their effectiveness may depend upon their placement in the working room. They concluded that these determinants may therefore need more investigation than others. The high discrepancy in Weight fraction of NOAA in the product observed in our study was the result of a misunderstanding of this item in the Logbook. Instead of indicating the percentage of NOAA in the product, two of the evaluators indicated the percentage of purity of NOAA or the percentage of impurities.

Our work has led to an improvement of the standardized tool (Onsite technical logbook) and to the development of an explanatory guideline document for completing the Onsite technical logbook when implementing the EpiNano method in companies by external or new evaluators (provided in Supplementary Information, Document S3 at Annals of Work Exposures and Health online). Two training sessions were conducted to codify the exposure determinants causing discrepancies in quantitative exposure scores, first in the logbook and then using EpiNano data entry software. During these sessions different scenarios were considered, individually codified and then collectively discussed until all participants agreed and understood the correct codification mechanism. Clear instructions were then formulated and written within the explanatory guideline document, all important variables requiring precise coding, unit, or description being emphasized. The onsite technical logbook was modified for three variables (weight fraction of NOAA, ventilation, and local exposure control) using more precise terminology and examples added to each item. 


\section{Conclusions}

This study showed the satisfactory reliability of the EpiNano method to identify workstations potentially concerned by exposure to CNTs with high sensitivity and specificity, as well as the satisfactory inter-rater reliability among evaluators from the EpiNano team for binary, semiquantitative, and quantitative exposure assessment. Conducted at the beginning of the national epidemiological program EpiNano, the inter-rater reliability study was useful not only to evaluate but also to improve this observational method and the standardized tool-the Onsite technical logbook. Computation of reliability coefficients for each pair of evaluators revealed that the external unexperienced evaluator participating in this study compared poorly with the inner-EpiNano team evaluators. This underlines the importance of training for all new evaluators using EpiNano method by providing explanatory guidelines for its use. This study provides the first reliability assessment of the EpiNano method. However, to further validate this method, comparisons with robust quantitative exposure measurement data from the industrial facilities dealing with CNTs and other types of NOAA are necessary.

\section{Supplementary Data}

Supplementary data are available at Annals of Work Exposures and Health online.

\section{Acknowledgements}

The authors gratefully acknowledge the contribution of M. Ricaud, S. Malard from INRS, and O. Le Bihan from Ineris who supported this study and reviewed the manuscript. The help and advises of D.B. Richardson from the University of North Carolina in the manuscript revision is also acknowledged. This study was carried out with funding from the French Ministry of Health to the French Institute for Public Health Surveillance for the EpiNano program. The participation of scientists from CEA, INRS, and the University of Bordeaux was supported by these institutions as part of the collaboration on actions of common interest Quintet ExpoNano.

\section{Conflict of Interests}

The authors declare no conflict of interest relating to the material presented in this article. Its contents, including any opinions and/or conclusions expressed, are solely those of the authors.

\section{References}

Bekker C, Kuijpers E, Brouwer DH et al. (2015) Occupational exposure to nano-objects and their agglomerates and aggregates across various life cycle stages; a broad-scale exposure study. Ann Occup Hyg; 59: 681-704.
Bourgkard E, Wild P, Gonzalez M et al. (2013) Comparison of exposure assessment methods in a lung cancer case-control study: performance of a lifelong task-based questionnaire for asbestos and PAHs. Occup Environ Med; 70 : 884-91.

Brenner H, Gefeller O. (1997) Variation of sensitivity, specificity, likelihood ratios and predictive values with disease prevalence. Stat Med; 16: 981-91.

Brouwer DH, Van Duuren-Stuurman B, Berges M et al. (2013) Workplace air measurements and likelihood of exposure to manufactured nano-objects, agglomerates, and aggregates. $J$ Nanopart Res; 15: 2090.

Brown MB, Forsythe AB. (1974) Robust tests for equality of variances. J Am Stat Assoc; 69: 364-7.

Burstyn I, Slutsky A, Lee DG et al. (2014) Beyond crosswalks: reliability of exposure assessment following automated coding of free-text job descriptions for occupational epidemiology. Ann Occup Hyg; 58: 482-92.

Canu IG, Boutou-Kempf O, Delabre L et al. (2013) French registry of workers handling engineered nanomaterials as an instrument of integrated system for surveillance and research. J Phys Conf Ser; 429: 012066.

Cohen J. (1968) Weighted kappa: nominal scale agreement with provision for scaled disagreement or partial credit. Psychol Bull; 70: 213-20.

Cohen J. (1988) Statistical power analyses for the behavioral sciences. 2nd edn. Hillsdale, NJ: Lawrence Erlbaum Associates.

Dahm MM, Evans DE, Schubauer-Berigan MK et al. (2013) Occupational exposure assessment in carbon nanotube and nanofiber primary and secondary manufacturers: mobile direct-reading sampling. Ann Occup Hyg; 57: 328-44.

Donner A, Wells G. (1986) A comparison of confidence interval methods for the intraclass correlation coefficient. Biometrics; 42: 401-12.

Duuren-Stuurman BV, Vink SR, Verbist KJM et al. (2012) Stoffenmanager nano version 1.0: a web-based tool for risk prioritization of airborne manufactured nano objects. Ann Occup Hyg; 56: 525-41.

Fleiss JL. (1999) Reliability of measurement. In The design and analysis of clinical experiments. Hoboken, NJ: John Wiley \& Sons, Inc. pp. 1-32.

Guseva Canu I, Bateson T, Bouvard V et al. (2015a) Human exposure to carbon-based fibrous nanomaterials: a review. Int J Hyg Environ Health; 219: 166-75.

Guseva Canu I, Burstyn I, Richardson D (2016) The order of things: control bands for risk managers and scientists. Epidemiology; 27: 765-8.

Guseva Canu I, Ducamp S, Delabre L et al. (2015b) Proposition d'une méthode de repérage des postes de travail potentiellement exposant aux nanoobjets, leurs agrégats ou agglomérats dans les entreprises mettant en oeuvre des nanomateriaux manufactures. Arch Malad Prof Environ; 76: 329-36.

Guseva Canu IG, Ducros C, Ducamp S et al. (2015c) A standardized non-instrumental tool for characterizing workstations concerned with exposure to engineered nanomaterials. J Phys Conf Ser; 617: 1-6. 
Honnert B, Grzebyk M. (2014) Manufactured nano-objects: an occupational survey in five industries in France. Ann Occup Hyg; 58: 121-35.

Hunt PR, Friesen MC, Sama S et al. (2015) Log-linear modeling of agreement among expert exposure assessors. Ann Occup Hyg; 59: 764-74.

InVS. (2013) Onsite technical logbook. [EpiNano project website; Standardized tool for exposure data collection]. Available at http://www.invs.sante.fr/Dossiers-thematiques/ Travail-et-sante/Epinano-Dispositif-de-surveillance-epidemiologique-des-travailleurs-potentiellement-exposes-auxnanomateriaux. Accessed 30 October 2015.

Landberg HE, Berg P, Andersson L et al. (2015) Comparison and evaluation of multiple users' usage of the exposure and risk tool: Stoffenmanager 5.1. Ann Occup Hyg; 2015. doi: 10.1093/annhyg/mev027

Landis JR, Koch GG. (1977) The measurement of observer agreement for categorical data. Biometrics; 33: 159-74.

Liao HY, Chung YT, Lai CH et al. (2014a) Sneezing and allergic dermatitis were increased in engineered nanomaterial handling workers. Ind Health; 52: 199-215.

Liao HY, Chung YT, Lai CH et al. (2014b) Six-month follow-up study of health markers of nanomaterials among workers handling engineered nanomaterials. Nanotoxicology; 8: 100-10.

Marquart H, Heussen H, Le Feber M et al. (2008) 'Stoffenmanager', a web-based control banding tool using an exposure process model. Ann Occup Hyg; 52: 429-41.

Nieuwenhuijsen MJ. (2003) Exposure assessment in occupational and environmental epidemiology. Oxford: Oxford University Press.

OECD. (2015). Harmonized tiered approach to measure and assess the potential exposure to airborne emissions of engineered nano-objects and their agglomerates and aggregates at workplaces. Paris, France: Organisation for Economic Co-operation and Development; Series on the Safety of Manufactured Nanomaterials-N55-ENV/JM/ $\operatorname{MONO}(2015) 19$, p. 51.

Rajaraman P, Samet P. (2005) Quality control and good epidemiological practice. In Ahrens W, Pigot I, editors. Handbook of epidemiology. Berlin: Springer. pp. 503-56.

Riedmann RA, Gasic B, Vernez D (2015) Sensitivity analysis, dominant factors, and robustness of the ECETOC TRA v3, Stoffenmanager 4.5, and ART 1.5 occupational exposure models. Risk Anal; 35: 211-25.

Schneider T, Brouwer DH, Koponen IK et al. (2011) Conceptual model for assessment of inhalation exposure to manufactured nanoparticles. J Expo Sci Environ Epidemiol; 21: 450-63.

Spearman C (1904) The proof and measurement of association between two things. Am J Psychol; 15: 72-101.

White E, Armstrong BK, Saracchi R (2008) Principles of exposure measurement in epidemiology. 2nd edn. Oxford: Oxford University Press.

Wild P, Schill W, Bourgkard E et al. (2016) The 2-phase casecontrol design: an efficient way to use expert-time. Scand J Work Environ Health; 42: 162-9.

Wu WT, Liao HY, Chung YT et al. (2014) Effect of nanoparticles exposure on fractional exhaled nitric oxide (FENO) in workers exposed to nanomaterials. Int J Mol Sci; 15 : 878-94.

Zimmermann E, Derrough S, Locatelli D et al. (2012) Results of potential exposure assessements during the maintenance and cleanout of deposition equipment. J Nanopart Res; 14 : $1-17$. 